\title{
Management of supratentorial epidural hematoma in children Report on 49 patients
}

\author{
Wellingson Silva Paiva, Almir Ferreira de Andrade, \\ Luis Mathias Júnior, Vinicius Monteiro de Paula Guirado, \\ Robson Luis Amorim, Nadia Nader Magrini, Manoel Jacobsen Teixeira
}

\begin{abstract}
Traumatic head injury is a common cause of mortality and acquired neurological impairment in children. However, pediatric epidural hematomas (EDHs) are not common and few series have studied the evolution of these patients. In this study, we present the results from a sample of patients with EDH with long-term follow-up. Method: Between January 2006 and December 2008, 49 patients with traumatic EDH were treated at our unit. Clinical course, radiological findings and outcomes were evaluated. Neurological status was assessed using the Glasgow Coma Scale (GCS). The patients' ages ranged from one day to 16 years. The mean follow-up was six months. Results: On admission, most of the patients presented mild trauma and $57 \%$ had a GCS of 13-15. The most common symptom was irritability. The most frequent mechanisms of injury were: falling from a height in 29 cases and motor vehicle accidents in 16 cases. Three of these patients presented GCS 3, but only one died. We found a late neurological deficit in nine patients. Conclusion: These lesions may occur following mild head trauma and in alert children with nonfocal neurological examinations. However, in children presenting irritability with subgaleal hematomas and a history of loss of consciousness, skull computed tomography must be performed.
\end{abstract}

Key words: epidural hematoma, head trauma, children.

Tratamento de hematoma epidural supratentorial em crianças: avaliação em 49 pacientes

\section{RESUMO}

Trauma craniocerebral é uma causa frequente de mortalidade e comprometimento neurológico adquirido em crianças. No entanto, hematomas epidurais (HED) são raros em pacientes pediátricos, com poucas series estudando a evolução destes pacientes. Neste estudo, os autores apresentam os resultados de uma casuística de pacientes com HED acompanhados em longo prazo. Método: Entre janeiro de 2006 e dezembro de 2008, 49 pacientes com HED foram tratados em nossa unidade. Curso clínico, achados radiológicos, e resultados foram avaliados. O estado neurológico foi avaliado com o Glasgow Coma Scale (GCS). A idade variou de 1 dia a 16 anos. A média de acompanhamento foi de 6 meses. Resultados: Na admissão, a maioria dos pacientes apresentava trauma leve e 57\% estavam com GCS de 13-15. O sintoma mais comum foi irritabilidade. Os mecanismos de trauma mais frequentes foram queda de altura em 29 casos e acidentes de trânsito em 16 casos. Três destes pacientes apresentavam GCS 3, mas somente um morreu. Verificou-se déficit neurológico tardio em nove pacientes. Conclusão: Esta lesão pode ocorrer após traumas leves e em crianças alerta com exames neurológicos não focais. No entanto, em crianças com irritabilidade com hematoma subgaleal e história de perda de consciência, tomografia do crânio deve ser realizada.

Palavras-chave: criança, hematoma epidural, trauma craniocerebral. 
Traumatic head injury is a common cause of mortality and acquired neurological impairment in children ${ }^{1}$. However, pediatric acute epidural hematomas (EDHs) are not common and, when they occur, they often present atypically ${ }^{2,3}$. The reported incidence of EDH after head trauma in hospitalized children ranges from $1 \%$ to $6 \%$. However some authors have reported an increased incidence of unassociated EDH over recent years ${ }^{5,6}$. Its diagnosis can be quite challenging because its clinical presentation is usually subtle and nonspecific. In this study, we present the results from a sample of children with EDH with long-term follow-up.

\section{METHOD}

All children (less than 16 years of age) diagnosed with traumatic epidural hematoma on computed tomography (CT) scans who were admitted to our hospital over the study period were included. Between January 2006 and December 2008, 49 patients with traumatic EDH were treated. Clinical course, radiological findings and outcomes were evaluated. Neurological status was assessed using the Glasgow Coma Scale (GCS). All the patients were treated in accordance with a standard advanced trauma life support protocol if they presented directly to the emergency department of our institution. The indication for ventilation was a neurological GCS score $<8$, or respiratory or cardiovascular impairment. The trauma workup was started in accordance with the clinical status and the mechanism of the trauma, and it usually included head and body CT scans and abdominal ultrasound. The patients' ages ranged from one day to 16 years. The mean follow-up was six months. Patients with spontaneous EDH, EDH of unknown etiology or infratentorial EDH were excluded from our current study.

Patient management was either surgical or conservative based on the children's clinical condition, GCS score, evidence of midline shift on the initial head CT scan and size of the EDH. Conservative management consisted of close observation in either a neonatal or a pediatric intensive care environment, with heart rate, respiratory rate and oxygen saturation monitoring in addition to frequent neurological clinical examinations and serial head CT scans.

\section{RESULTS}

Over this period, 49 patients with epidural hematomas were admitted to our hospital. On admission, most of the patients (57\%) had a GCS of 13-15, and 33\% of the patients had severe traumatic brain injury (TBI) (Table 1). Among the patients with mild head trauma, the most common presenting symptom was irritability, which occurred in $19 / 28$ (68\%) of them (Table 2). Thirty patients (61\%) patients had a skull fracture. There were 26 males and 23 females. With regard to the lateralization of the
Table 1. Patient distribution according to Glasgow Coma Scale (GCS) score.

\begin{tabular}{cc}
\hline TBI classification & Number of patients \\
\hline GCS 13-15 & 28 \\
GCS 9-12 & 5 \\
GCS 3-8 & 16 \\
\hline
\end{tabular}

TBI: traumatic brain injury.

Table 2. Patient distribution according to symptoms at hospital admission.

\begin{tabular}{cc}
\hline Symptom & Number of patients \\
\hline Irritability & 28 \\
Subgaleal hematoma & 23 \\
Lethargy & 5 \\
Coma & 16 \\
Pupil abnormality & 4 \\
Hemiparesis & 1 \\
\hline
\end{tabular}

Table 3. Patient distribution according to epidemiological and radiological features.

\begin{tabular}{cc}
\hline Glasgow Coma Scale (GCS) & Number of patients \\
\hline DEATH (GCS 1) & 1 \\
GCS 2 & 0 \\
GCS 3 & 2 \\
GCS 4 & 7 \\
GCS 5 & 39 \\
\hline
\end{tabular}

Table 4. Patient distribution according to outcome and follow-up.

\begin{tabular}{lc}
\hline Patients' features & Number of patients \\
\hline Sex & 26 \\
Male & 23 \\
Female & \\
Location of hematoma & 8 \\
Frontal & 9 \\
Temporal & 31 \\
Temporoparietal & 1 \\
Occipital & 3 \\
Associated lesion & 46 \\
No other intracranial lesion & 30 \\
Skull fracture & 19 \\
No skull fracture & \\
Thickness of hematoma & 26 \\
$<10$ mm & 23 \\
$>10$ mm &
\end{tabular}




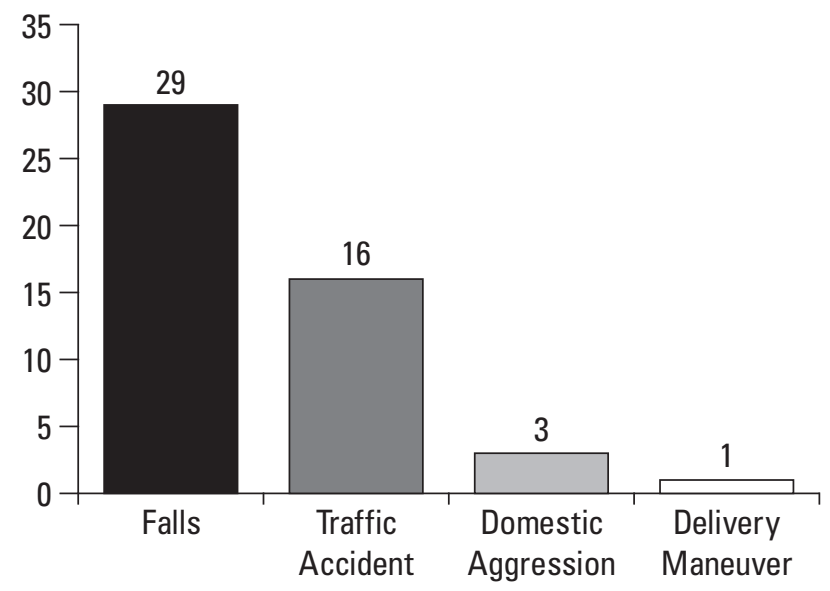

Figure. Patient distribution according to trauma mechanism.

hematoma in our study, 29/49 (59.1\%) were located on the right side, and the remaining $40.9 \%$ were located on the left side, while the temporal-parietal area was the most common anatomical location for the hematoma (Table 3).

Skull fractures were seen on CT in 30 patients (61\%). The most common sites were the parietal bone (18) and the temporal bone (8). The size of the EDH was found to be more than $2 \mathrm{~cm}$ in 19/49 patients, between 1 and $2 \mathrm{~cm}$ in $4 / 49$ and less than $1 \mathrm{~cm}$ along its largest diameter in $26 / 49$.

Two children with epidural hematomas suffered acute neurological deterioration, which occurred within 8 hours of the head trauma.

Over the patients' evolution, we found that one patient died. In terms of the Glasgow Coma Scale, 39 patients presented complete recovery, while seven patients had GCS 4 and two patients had severe neurological sequelae. The group of patients who underwent craniotomy had the worst prognosis: these patients presented large hematomas and lower scores on the GCS. Eleven patients in the surgical group had severe TBI, while only five patients undergoing medical management had severe TBI (Table 4).

The mechanisms of injury in our series were: falling from a height in 29 cases (59\%), motor vehicle accidents in 16 cases (33\%), obstetric maneuver during delivery in one case (2\%), and domestic accident/aggression in three cases (6\%) (Figure).

Associated lesions (subdural or contusion hematoma) were found in seven patients, and five of these were in the surgical group, presenting worse evolution during followup. Only five patients presented associated systemic injuries: two cases of upper limb fractures, one case of lower limb fracture, one case of pulmonary contusion and one case of closed abdominal trauma that did not need surgery.

\section{DISCUSSION}

It is well known that acute epidural hematomas in children are a rare and potentially life-threatening complication resulting from head injuries. These intracranial lesions in children represent 2 to 3\% of all head injury complications ${ }^{1,6}$.

Consistently with other series, falls were the most common cause of trauma in our series. Pasaoglu et al. ${ }^{7}$ found that falls were the most common underlying mechanism in $63 \%$ of their pediatric cases, and Ersahin et al. ${ }^{8}$ identified falls as the most common mechanism of injury in $62 \%$ of their pediatric cases. It is noteworthy is that almost $60 \%$ of the EDHs in our study were related to accidents at home or within a familial environment. Only roughly one third of the accidents were traffic-related.

Among the patients admitted with mild head trauma, $68 \%$ presented symptoms of irritability alone and almost $60 \%$ were alert with non-focal neurological examinations. Previous studies on patients with head trauma also demonstrated that serious intracranial injury may occur following minor head trauma among alert patients. This group of patients represents a great challenge for pediatric emergency teams. Miller et al. ${ }^{9}$ reported that 183 patients with intracranial hemorrhage after "minor" head injury arrived in an alert condition with a GCS score of 15; 57\% had no clinical signs. Likewise, Cook et al. ${ }^{10}$ reported that among 100 patients with traumatic epidural hematoma and GCS of 14 or $15,40 \%$ had nausea or vomiting but no focal neurological signs. Although it is desirable to have cranial CT scans for all patients with TBI, it can be recognized that this is not viable everywhere. The criteria for indicating CT scans involve not only medical and legal issues but also cost ${ }^{11}$. Therefore, some authors have advised that CT scans should only be performed on subsets of patients who are considered to be at higher risk of developing intracranial lesions ${ }^{12,13}$. Others have maintained that failure to systematically perform CT scans for TBI implies a certain rate of misdiagnosis that has to be weighed against the reduction in $\operatorname{cost}^{14}$. Thus, protocols for the use of CT scans to assess cases of mild head injury (MHI) vary among institutions and countries, depending on the local cost-effectiveness analysis. In our institution, as reported on previous occasions, there is a liberal policy. Hence, cranial CT scans are advised for almost all patients with MHI whose trauma is perceived as nontrivial by the attending emergency physician or neurosurgeon, using criteria that include GCS, trauma mechanism, age and lucidity ${ }^{11,15}$.

The criteria for how to select cases for either conservative or surgical treatment remain controversial. Chen et al. ${ }^{16}$ suggested that a hematoma volume larger than $30 \mathrm{ml}$ with a thickness of more than $15 \mathrm{~mm}$ and a midline shift of more than $5 \mathrm{~mm}$ constitutes a strong indication for 
surgical treatment. Similarly, Bejjani et al. ${ }^{17}$ found that the most important radiographic parameters dictating surgical evacuation were a maximum hematoma diameter of more than $18 \mathrm{~mm}$ and a midline shift of more than $4 \mathrm{~mm}$. Our policy for treating EDH is somewhat different. In our series, 23 patients (47\%) underwent a neurosurgical operation and 26 underwent conservative treatment. The criteria adopted for conservative management were hematoma thickness less than $10 \mathrm{~mm}$ and midline shift less than $5 \mathrm{~mm}$. In two patients in whom we observed neurological deterioration and increasing hematoma thickness, we performed emergency craniotomy with hematoma evacuation, and these patients presented GCS 5 in the follow-up. We believe that conservative management can only be performed in an intensive care unit environment in hospitals with neurosurgical attendance. A new skull CT scan needs to be performed 12-24 hours after the first examination.

Children sustaining cranial trauma associated with EDH constitute a heterogeneous group with a variety of clinical outcomes ${ }^{18}$. The outcomes among the children in our series were encouraging. Despite potentially lifethreatening intracranial hemorrhages, there was only one death: a patient who was admitted with a GCS score of 3 points and nonreactive pupils. There was also relatively low morbidity: no children were in a vegetative state. The approximate mortality rate was $5 \%$, although mortality in the literature consulted ranged from $0 \%$ to $12 \%{ }^{19,20}$ and was even higher in the pre-CT era ${ }^{18}$. From our series, we believe that if lesions are treated early, and aggressively in cases with worse consciousness, improved outcomes can be achieved.

In a similar study conducted in our unit two decades ago, surgical treatment was performed more often, possibly because it was more difficult to repeat CT scans at that time. Thus, craniotomy was performed on $74 \%$ of patients, while in our current study, craniotomy was required in $46 \%$ of the cases. In the same study covering the period from 1987 to 1991, most of the patients managed without surgery underwent $\mathrm{CT}$ more than 12 hours after the trauma (60\%), whereas in our series, only two patients underwent CT more than 12 hours after the trauma, and the two cases were from another institution. The time taken to admit cases to hospital has also decreased, thus indicating greater organization within the rescue system 20 years on. An X-ray of the head was performed on 43 patients before the CT scan in the earlier series, while in the present series, only three cases underwent X-ray imaging before tomography, and two of these were from another institution. This also indicates that access to tomography has become simplified, along with a tendency not to use skull X-rays in head trauma cases.

Comparing the results from these two studies in our unit (1987-1991 versus 2006-2008) ${ }^{6}$, we found that falls continued to be a common cause of trauma, but that there had been significant growth in the proportion of cases due to automobile accidents (from 1.7\% to 33\%). This can perhaps be explained by the large increase in the vehicle fleet in our city that has taken place over this interval. Regarding the outcomes, there was no significant difference in the mortality rate (3.4\% versus $2.5 \%$ ) over the decades that separated the samples. However, a smaller proportion of aggressive treatment (craniotomy) was required to achieve equivalent functional outcomes.

One of our patients was a full-term newborn with a skull fracture and large epidural hematoma secondary to forceps delivery. EDH in newborn infants is a very rare condition. In a study on a series of newborns with epidural hematomas, Heyman et al. ${ }^{21}$ stated that when the hematoma was more than $1 \mathrm{~cm}$ thick and more than 4 $\mathrm{cm}$ long in the anteroposterior orientation or associated with a depressed cranial fracture, surgery should be performed, given that it is well known that most brain damage is caused by mechanical pressure. In this patient of ours, the dimensions of the hematoma and its association with a depressed skull fracture indicated surgical treatment.

EDH can be managed with excellent outcomes, even in children. This lesion may occur after relatively minor head trauma and in alert children with nonfocal neurological examinations. However, in children presenting irritability with subgaleal hematoma and a history of loss of consciousness, skull CT must be performed. The neurological condition and the size of the EDH seen on head CT scans are the most commonly used criteria for correct management.

\section{REFERENCES}

1. Parslow RC, Morris KP, Tasker RC, Forsyth RJ, Hawley CA. On behalf of the UK, Peadiatric Traumatic, Brain Injury, Study Steering, Group and the Paediatric, Intensive Care, Society Study Group. Epidemiology of traumatic brain injury in children receiving intensive care in the UK. Arch Dis Child 2005;90:1182-1187.

2. Duhaime AC, Alario AJ, Lewander WJ, et al. Head injury in very young children: mechanisms, injury types, and ophthalmologic findings in 100 hospitalized patients younger than 2 years of age. Pediatrics 1992;90: 179-185.

3. Reece RM, Sege R. Childhood head injuries. Accidental of inflicted? Arch Pediatr Adolesc Med 2000;154:11-15.

4. Maggi G, Aliberti F, Petrone G, et al. Extradural hematomas in children. J Neurosurg Sci 1998;42:95-99.

5. Stieg PE, Kase CS. Intracranial hemorrhage: diagnosis and emergency management. Neurol Clin 1998;16:373-390.

6. dos Santos AL, Plese JP, Ciquini JO, et al. Extradural hematomas in children. Pediatr Neurosurg 1994;21:50-54.

7. Pasaoglu A, Orhon C, Koc K, Selcuklu A, Akdemir H, Uzunoglu H. Traumatic extradural haematomas in pediatric age group. Acta Neurochir (Wien) 1990;106:136-139

8. Ersahin Y, Mutluer S, Guzelbag E. Extradural hematoma: analysis of 146 cases. Childs Nerv Syst 1993;9:96-99.

9. Miller JD, Murray LS, Teasdale GM. Development of a traumatic intracranial hematoma after a "minor" head injury. Neurosurgery 1990;27:669-673. 
10. Cook RJ, Borsch WC, Fearnside MR, et al. Outcome prediction in extradural haematomas. Acta Nourochir 1988;95:98-94.

11. de Andrade AF, de Almeida AN, Bor-Seng-Shu E, Lourenço L, Mandel M, Marino R Jr. The value of cranial computed tomography in high-risk, mildly head-injured patients. Surg Neurol 2006;65 (Suppl 1):S10-S13.

12. Haydel MJ, Preston CA, Mills TJ, Luber S, Blaudeau E, DeBlieux PM. Indications for computed tomography in patients with minor head injury. N Engl J Med 2000;343:100-105.

13. Stiell IG, Wells GA, Vandemheen K, et al. The Canadian CT Head Rule for patients with minor head injury. Lancet 2001;357:1391-1396.

14. Ibanez J, Arikan F, Pedraza S, et al. Reliability of clinical guidelines in the detection of patients at risk following mild head injury: results of a prospective study. Neurosurgery 2004;100:825-834.

15. de Andrade AF, Marino R, Ciquini O, Figueiredo EG, Machado AG. Guidelines for neurosurgical trauma in Brazil. World J Surg 2001;25:1186-1201.

16. Chen TY, Wong CW, Chang CN, et al. The expectant treatment of as- ymptomatic supratentorial epidural hematomas. Neurosurgery 1993;32: 176-179.

17. Bejjani GK, Donahue DJ, Rusin J, et al. Radiological and clinical criteria for the management of epidural hematomas in children. Pediatr Neurosurg 1996;25:302-308.

18. Gerlach R, Dittrich S, Schneider W, Ackermann H, Seifert V, Kieslich M. Traumatic epidural hematomas in children and adolescents: outcome analysis in 39 consecutive unselected cases. Pediatr Emerg Care 2009;25:164-169.

19. Browne GJ, Lam LT. Isolated extradural hematoma in children presenting to an emergency department in Australia. Pediatr Emerg Care 2002;18: 86-90.

20. Bullock MR, Chesnut R, Ghajar J, et al. Surgical management of acute epidural hematomas. Neurosurgery 2006:58 (Suppl):S7-S15.

21. Heyman R, Heckly A, Magagi J, Pladys P, Hamlat A. Intracranial epidural hematoma in newborn infants: clinical study of 15 cases. Neurosurgery 2005:57:924-929. 